\title{
Coupling of high-resolution meteorological and wave models over southern Italy
}

\author{
L. Bertotti ${ }^{1}$, M. M. Miglietta ${ }^{2}$, and S. Davolio ${ }^{3}$ \\ ${ }^{1}$ Institute of Marine Sciences, ISMAR - CNR, Venice, Italy \\ ${ }^{2}$ Institute of Atmospheric Sciences and Climate, ISAC - CNR, Lecce, Italy \\ ${ }^{3}$ Institute of Atmospheric Sciences and Climate, ISAC - CNR, Bologna, Italy \\ Received: 6 October 2008 - Revised: 19 May 2009 - Accepted: 23 July 2009 - Published: 28 July 2009
}

\begin{abstract}
In the framework of RISKMED project, three different high-resolution limited area meteorological models (BOLAM, MOLOCH and WRF) have been run over southern Italy for the retrospective analysis of three case studies characterized by strong winds and severe wave conditions in the Ionian, southern Adriatic and southern Tyrrhenian seas. All the models were able to reproduce the main meteorological features of each event.

The wind fields simulated by the meteorological models and those provided by the ECMWF analysis have been ingested into a wave model (WAM) for the hindcast of the main wave parameters. The results have been compared with the observations of three buoys whose measurements were available in the area of interest.

A remarkable improvement in the representation of the significant wave height came out using the limited area model data with respect to the simulations where the ECMWF analyses were used as forcing. Among the limited area models, the BOLAM-MOLOCH modelling system provided slightly better performances. From the limited set of simulations, the different model predictions came out closer to each other and more skilful in areas where the waves approach the coastline perpendicularly from the open sea.
\end{abstract}

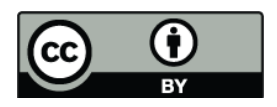

Correspondence to: L. Bertotti (luciana.bertotti@ismar.cnr.it)

\section{Introduction}

Beyond the range of few hours, weather forecasts are based on the use of numerical weather prediction (NWP) models. Such models solve numerically the physical equations describing the atmospheric motions and processes. They are usually divided into two major categories: global circulation models (GCMs) and limited area models (LAMs). GCMs have a global coverage but a coarse horizontal resolution, imposed by the limited computational resources. The task of describing the weather evolution with greater local accuracy is usually pursued by LAMs, which integrate the model equations only on a limited geographical domain. LAMs require the availability of boundary conditions (BCs), which prescribe the time evolution of the prognostic variables along the outer part of the integration domain. BCs are extracted from meteorological fields forecast by lower resolution GCMs or, in some cases, by coarser resolution LAMs. The application of high-resolution models allows a better representation of the small-scale forcing due to topographic features, and of the dynamics and physics affecting the smaller scales, producing a physically consistent downscaling of the larger scale forecasts.

The main aim of the INTERREG European project RISKMED (www.riskmed.net) was the implementation of a warning system for issuing alerts in case of severe weather events, such as heavy precipitation, wind storms and high waves. Although a true meteorological ensemble prediction system was out of the scope, two weather-prediction chains have been implemented in similar configurations over southern Italy (in particular Calabria and Apulia regions and surrounding seas), with the purpose of producing operational high-resolution forecasts up to $72 \mathrm{~h}$. The two modelling

Published by Copernicus Publications on behalf of the European Geosciences Union. 
Table 1. Meteorological model grid configuration.

\begin{tabular}{lcccc}
\hline MODEL & $\begin{array}{c}\text { Horizontal } \\
\text { Resolution }(\mathrm{km})\end{array}$ & Grid Points & Levels & Center (lon, lat) \\
\hline BOLAM & 16 & $103 \times 103$ & 40 & $(16.10,40.40)$ \\
MOLOCH & 3.8 & $150 \times 162$ & 50 & $(17.10,39.79)$ \\
WRF-g1 & 16 & $108 \times 108$ & 31 & $(16.18,40.04)$ \\
WRF-g2 & 4 & $133 \times 161$ & 31 & $(17.63,39.81)$ \\
\hline
\end{tabular}

systems provided gridded wind fields over similar domains in order to force the only wave model available within the project.

The capability to produce an accurate estimate of the sea state is an important issue in terms of socio-economic impact in coastal areas with intense human activity. This is not a simple task when the area of interest is characterized by complex orography (Smith, 1979; Agustsson and Olafsson, 2009) and/or a rough coastline, as the skill of meteorological models in terms of wind field forecasting near the ground is significantly reduced in such regions. The use of a grid with the highest possible resolution compatible with the available computational resources improves the model representation of the topography and thus can enhance the quality of the meteorological forecasts. Concerning the wave model, the runs were downscaled using the nesting technique from a coarser grid covering the whole Mediterranean basin to a smaller area covering Calabria and Apulia regions (southern Italy) and Epirus (the Greek region facing the northern Ionian Sea). A similar approach has been already applied in the past in the Ligurian Sea where the nesting technique was used to evaluate the sea state along the coast of Liguria region. The results, not published, show that the use of higher resolution grids improve substantially the knowledge of the sea state in coastal areas. A similar technique has been applied for example by Federico et al. (2004, 2006), that analysed the influence of different resolutions in the hindcast of sea waves during stormy conditions in southern Italy.

The present study aims at evaluating the results provided by the different (meteorological-wave) forecasting systems available within the project. In order to attain this purpose, the modelling systems have been applied to different severe weather episodes. Three case studies have been selected, each one characterized by strong winds and severe wave conditions in the southern Tyrrhenian, Ionian and southern Adriatic seas. The final purpose of these simulations is to test the operational implementation of the high-resolution numerical modelling chains and to validate its results through comparison with local measurements, with the aim of providing correct warnings to the end-users with suitable advance in time.

The paper is organized as follows. In Sect. 2, a brief description of the models setup is provided. A synoptic analysis of the three case studies is presented in Sect. 3. In Sect. 4, the results obtained with the different models are compared in terms of both wind and waves forecasting; a comparison with the available observations is also provided. Finally, a summary is given in Sect. 5 .

\section{Model setup}

The meteorological forecasting systems considered in the present study are based on the application of the following meteorological limited area models:

- The hydrostatic model BOLAM, developed at CNRISAC and employed to run meteorological simulations at intermediate resolution.

- The non-hydrostatic model MOLOCH, developed at CNR-ISAC, one-way nested into BOLAM in a smaller domain and applied to simulations at higher horizontal resolution.

- The non-hydrostatic model WRF, developed in a cooperative effort coordinated by NCAR (USA); the version used at CNR-ISAC for the present project is ARW 2.1, implemented in a two-way nesting configuration.

A description of the modelling systems, BOLAM-MOLOCH and WRF, may be found in Davolio et al. (2007) and Skamarock et al. (2005), respectively.

The meteorological model configuration implemented in RISKMED has been determined by different requirements: the available computational resources, the need of highresolution runs and the necessity of a comparison among the results of the different models. Therefore, similar domains and grid resolutions have been chosen for the two different modelling systems, BOLAM-MOLOCH and WRF. The horizontal grid resolution is $16 \mathrm{~km}$ for the WRF coarse grid and BOLAM and about $4 \mathrm{~km}$ for the WRF inner grid and MOLOCH. The ECMWF (European Centre for Mediumrange Weather Forecasts) analysis/forecasts are used as initial/boundary conditions for the coarse resolution simulations. The boundary conditions are provided every three hours. The integration domains of the meteorological models are shown in Fig. 1a. The largest domain, which covers approximately the central Mediterranean basin, represents the integration area for the WRF coarse resolution domain and, approximately, for BOLAM. The WRF inner domain and MOLOCH grid cover the entire southern Italy and the adjacent seas, including Apulia and Calabria regions, two of the target areas of the project. The configurations for both the modelling systems are summarized in Table 1, while the parameterisation schemes for the three models are shown in Table 2.

Concerning the wave modelling, we used the WAM model. Developed by a group of scientists from different countries around the world, the model is presently used by most of the main meteorological centres to provide the wave 
Table 2. Parameterization schemes for the different models. Note that the convective parameterization is not active on the WRF inner grid.

\begin{tabular}{llll}
\hline Parameterisation & BOLAM & MOLOCH & WRF \\
\hline Microphysics & Schultz & Drofa and Malguzzi & Thompson et al. \\
Convection & Kain-Fritsch & $/$ & Kain-Fritsch (KF-Eta) \\
Longwave radiation & ECMWF+Geleyn & ECMWF and Geleyn & RRTM \\
Shortwave radiation & ECMWF+Geleyn & ECMWF and Geleyn & Dudhia \\
Boundary layer & E-l closure & E-l closure & Yonsei University (YSU) \\
Soil & 4-layer (Drofa et al.) & 4-layer (Drofa et al.) & 5-layer thermal-diffusion \\
\hline
\end{tabular}

forecast at global as well as at local scale. The master references are WAMDI Group (1988), Komen et al. (1994) and Janssen (2007). The requirements of the high resolution for a better definition of the weather and sea conditions led to the use of the nesting technique. For this reason two grids with different resolution have been considered when running the wave model. The coarser one covers the whole Mediterranean basin with resolution of $1 / 4^{\circ}$, while the inner one, centred over the area of interest, has a grid step of $1 / 16^{\circ}$. The last one is presented in Fig. 1b.

In order to test our system before an operational use, the whole procedure has been experimented with different weather conditions characterized by episodes of strong winds and high wave conditions. Three different periods have been selected: 9-15 December 2005, 17-20 April 2006 and 14 January 2007. These events affected the coastal areas of Apulia and Calabria regions and Epirus. For the two case studies of 17-20 April 2006 and 1-4 January 2007, the runs start at 12:00 UTC of the first day. Each run has produced a sequence of wind fields at 3-h interval for a total forecasting time of $72 \mathrm{~h}$. For the other case study of 915 December 2005, due to its longer duration (6 days), the wind fields have been produced by a sequence of runs each one lasting for $48 \mathrm{~h}$ and partly overlapping, starting respectively at: 00:00 UTC, 9 December; 12:00 UTC, 10 December; 00:00 UTC, 12 December; 12:00 UTC, 13 December. The wind fields, employed to force the WAM model, have been obtained by a forecast in the range $+12-+48 \mathrm{~h}$. Since the output of the meteorological models is not provided on a regular latitude-longitude grid, a preliminary interpolation is necessary to provide the wind fields at the WAM grid point.

Having adopted the nesting technique, the sea conditions at the border of the inner grid have to be known before running the WAM model on that domain. Because the area of interest is not completely surrounded by land but presents some open boundaries, we must expect that a certain amount of energy, e.g. waves, enters into the area through these borders. For these reasons a preliminary run needs to be done on a larger area, saving the sea conditions at the open boundaries of the nested grid. In our case the wave model has been run over the whole Mediterranean Sea using the coarser grid.

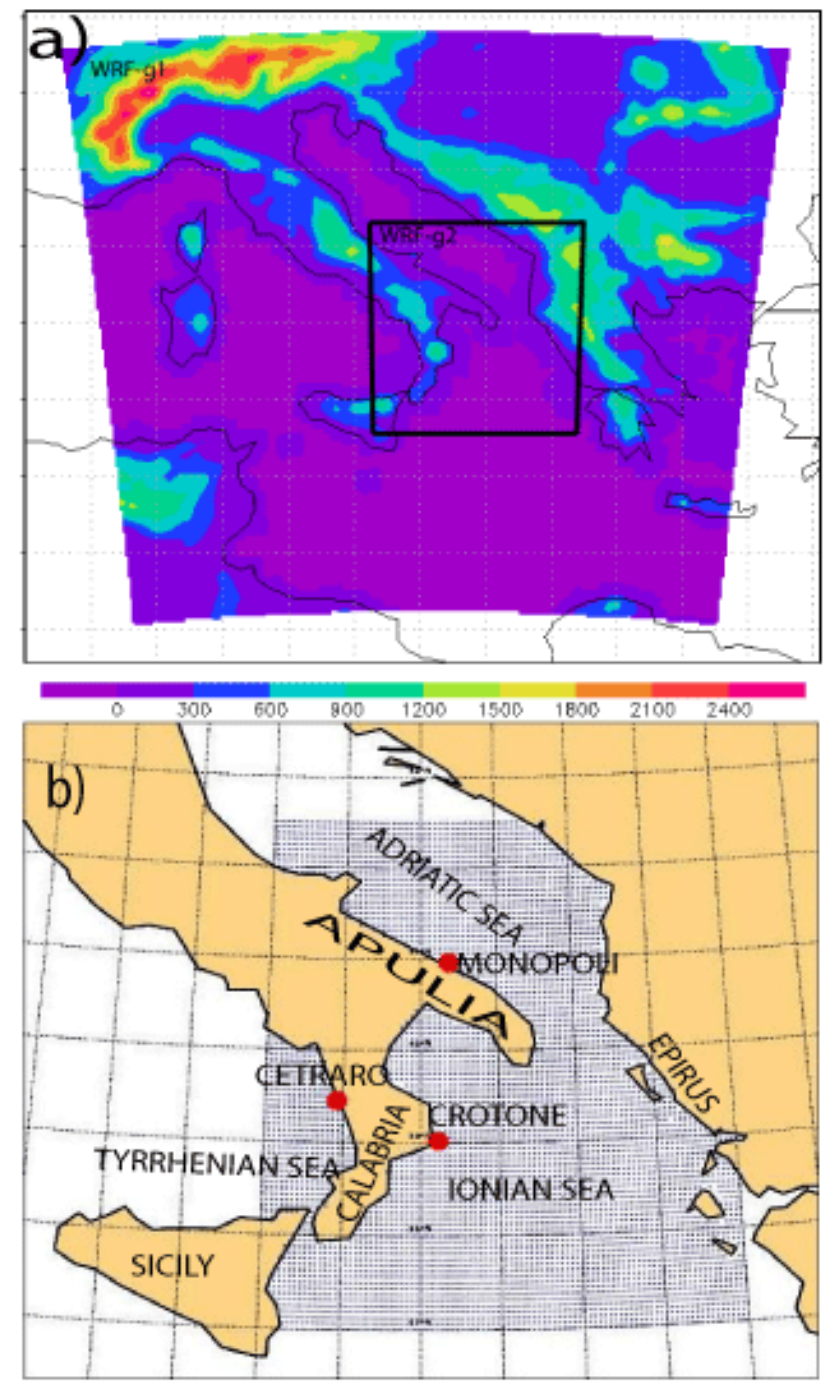

Fig. 1. (a) Model integration domains. This includes the topography of the outer grid. (b) WAM sea points $\left(\mathrm{step}=1 / 16^{\circ}\right)$ on the fine grid, where the model is forced with the LAMs; the red dots indicate the measurements sites. 


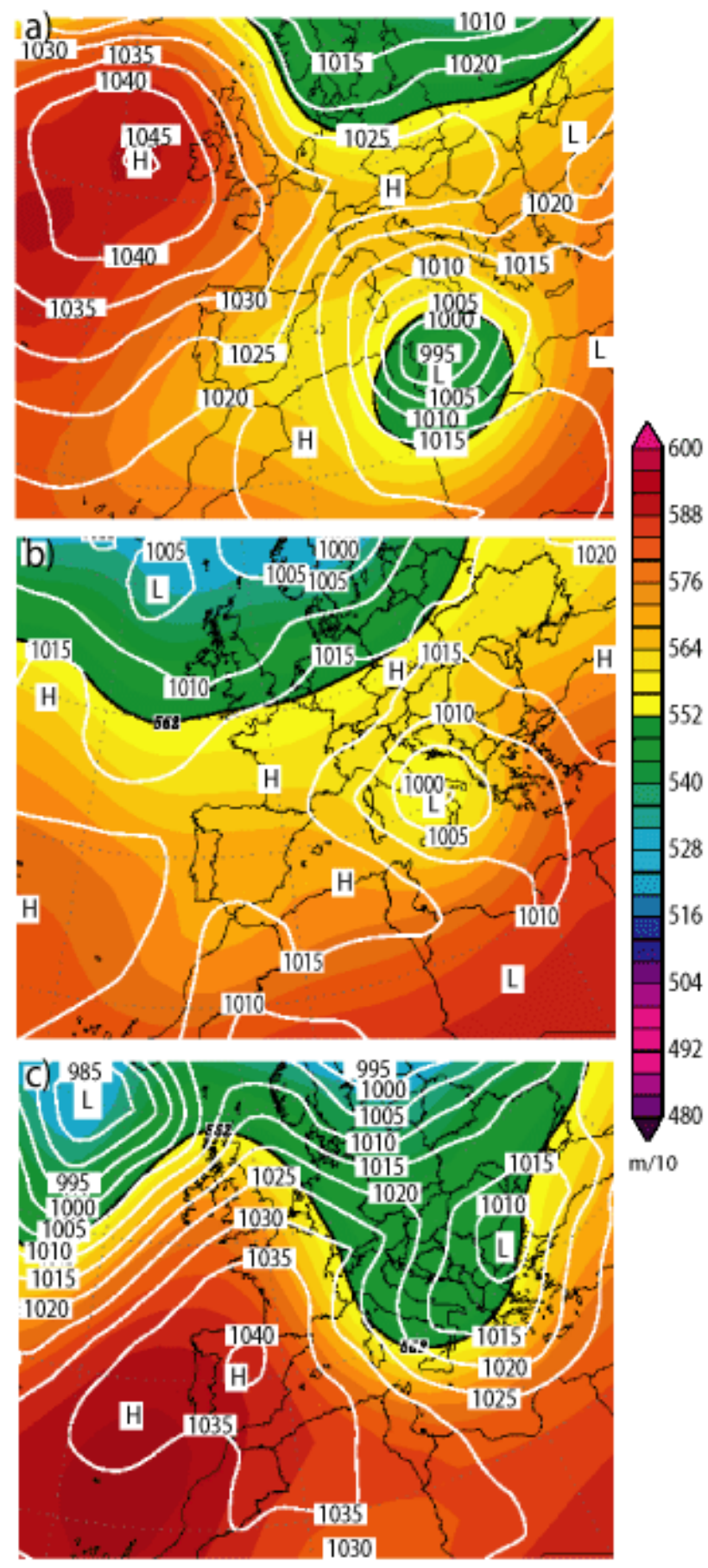

Fig. 2. The NCEP-NCAR (National Centre for Atmospheric Research-National Centre for Environmental Prediction) reanalysis (source: www.wetterzentrale.de): mean sea level pressure (in $\mathrm{hPa}$, white lines) and $500 \mathrm{hPa}$ geopotential height (in $\mathrm{m} / 10$, colours) at 00:00 UTC of: (a) 14 December 2005, (b) 19 April 2006 and (c) 3 January 2007.

A preliminary run of WAM has been done using as input the analysed surface wind from the ECMWF global meteorological model. Hence, the wave model has been run using, as input, the wind from the three different meteorological models, BOLAM, MOLOCH and WRF. The test runs have been repeated for each chosen stormy period.

Each simulation provides the evolution of the main wave parameters (significant wave height, mean flow direction and mean period) at 3-h interval. The output fields allow to compare the response of the wave model to the different wind inputs over the whole area. The model results have also been compared with in situ measurements. To attain this aim the wave parameters have also been saved at the location of three buoys (Fig. 1b): Monopoli, close to Apulia coast in the southern Adriatic Sea, Cetraro, near the coast of Calabria in the southern Tyrrhenian Sea and Crotone, close to the Ionian coast of Calabria.

\section{Synoptic analysis}

As mentioned before, three different periods characterized by heavy storms have been chosen to test the models. A brief description of the synoptic conditions observed during the three case studies is reported hereafter.

\subsection{9-15 December 2005}

The first event is characterized by two distinct phases of high waves, due to intense easterly flows affecting the Ionian Sea associated with a deep cyclonic circulation over the Mediterranean. At 00:00 UTC, 9 December 2005, a deep upper level trough extends from north-eastern Europe into the central Mediterranean basin; during the following $24 \mathrm{~h}$, the trough evolves into a deep cut-off low, centred between Tunisia and Sardinia. Thus, an intense cyclonic easterly lowlevel flow develops, associated with a low pressure centre localized over the southern Mediterranean Sea. At 00:00 UTC, 12 December, the pressure minimum has moved northward and is localized over the southern Tyrrhenian Sea, while a deep upper level cyclonic circulation affects the western and the central Mediterranean. On the following day, an outbreak of cold air from northern Europe feeds the cut-off again, and a deep low pressure system rapidly develops to the east of Tunisia, in phase with the upper level minimum on 14 December (Fig. 2a). At 00:00 UTC, 15 December, the minimum has partially filled in while moving eastward.

\section{$3.2 \quad$ 17-20 April 2006}

The second event is associated with the presence of a pressure minimum over the Ionian Sea. At 00:00 UTC, 18 April 2006, a high pressure centre is present over the Atlantic Ocean, marginally affecting Spain and France, while the main cyclonic circulation affects the northern Europe. Over the Mediterranean Sea, a low pressure system, significantly deepened during the previous $24 \mathrm{~h}$, is centred over Tunisia. The associated cyclonic circulation affects the 
central and southern Italian regions, forcing intense southsouth-easterly flow and waves in the Ionian Sea that reach a height of 3 meters at the peak of the storm (in the evening of 18 April). This pressure minimum is positioned to the east side of a weak upper level trough affecting the western Mediterranean Sea and rapidly moving eastward, so that in the following $24 \mathrm{~h}$ (Fig. 2b) the minimum further deepens while moving north-north-eastward. At the same time, also the upper level trough intensifies, originating a cut-off that gets in phase with the low level vortex, centred over southern Italy.

\subsection{1-4 January 2007}

The third event is characterized by the transit of a trough over the Italian peninsula. The synoptic situation at 00:00 UTC, 1 January 2007, presents a high pressure centre extending from the Atlantic Ocean into the central Mediterranean Sea both at low and upper levels. By the following day, the anticyclone shifts westward over the Atlantic Ocean, immediately to the west of the Iberian Peninsula, with its main ridge elongated from north-west to south-east. Consequently, the pressure weakens over the central Mediterranean Sea, with a minimum immediately to the lee side of the Alps. At upper levels, a trough is localized between France and Spain, associated with a strong pressure gradient, and moves into the Mediterranean. The whole pressure pattern shifts eastward $24 \mathrm{~h}$ later (Fig. 2c): an intense cyclonic circulation, associated with a deep low centred over Bulgaria, affects the central Mediterranean with a strong pressure gradient mainly localized between Tunisia and Calabria region and over the Ionian Sea. Here, strong north-westerly winds develop generating waves with about $4-5 \mathrm{~m}$ of significant wave height. At upper levels, a trough is now elongated from northern Europe into the Mediterranean and affects the whole Italian peninsula. After further $24 \mathrm{~h}$, the pressure pattern shifts farther eastward, so that the minimum is localized over the Black Sea and a residual cyclonic circulation over Italy remains confined only over the Ionian regions.

\section{Results}

Each one of the described storms has been simulated running the wave model using as input the wind produced by ECMWF, BOLAM, MOLOCH and WRF meteorological models. Both wind fields and wave-correlated fields (significant wave height, mean flow direction and mean period) have been compared for each time step. Because the wave fields are an integrated effect of the wind over the sea, the attention is mainly focused on the results of the wave model when driven by BOLAM, MOLOCH and WRF winds. As already mentioned above, the wind from ECMWF analyses has been used to run the wave model only in order to provide the boundary conditions for the nested run. Hence, the results
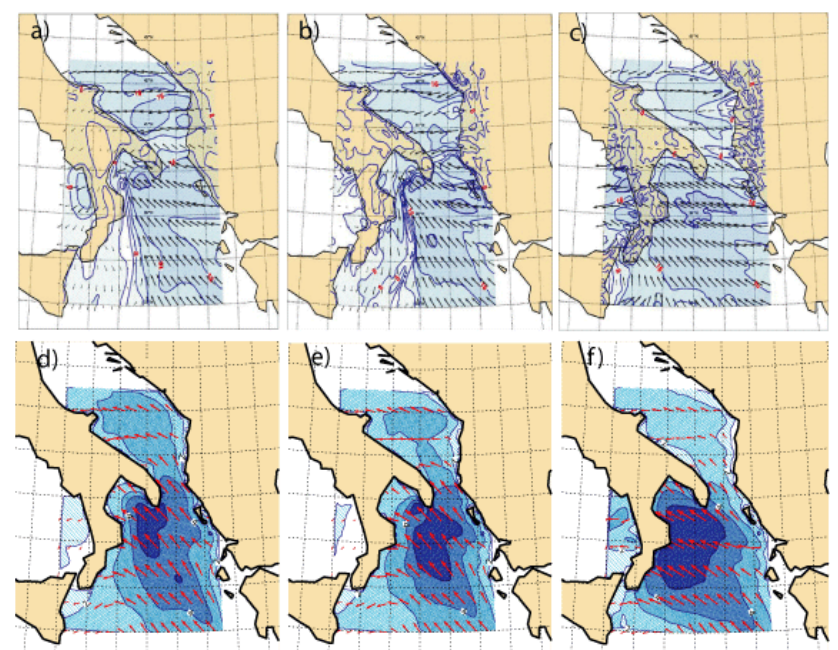

Fig. 3. Wind (top panels) and wave (bottom panels) fields at 12:00 UTC, 11 December 2005, corresponding to the peak of the storm: (a) BOLAM, (b) MOLOCH (c) WRF forecast wind (isotachs are plotted every $4 \mathrm{~m} \mathrm{~s}^{-1}$; the stronger the wind, the deeper the blue tone); wave heights forecast by WAM using (d) BOLAM, (e) MOLOCH and (f) WRF wind fields as input. Isolines of significant wave height are plotted every $1 \mathrm{~mm}$. Blue tones for different wave heights - the higher the waves, the darker the colour. Red arrows indicate the mean flow direction of waves.

of these runs, which have a resolution definitely coarser compared with the LAMs, will only be partially commented. A comparison with wave measurements is also performed. The results of the comparison are discussed hereafter for each storm.

\subsection{9-15 December 2005}

All the meteorological models are able to reproduce the meteorological evolution of the storm. We concentrate our discussion at 12:00 UTC, 11 December 2005, at the peak of the event. All the models reproduce correctly the prevailing easterly wind associated with the cyclonic circulation centred over the southern Mediterranean Sea (see Sect. 3.1), although some discrepancies emerge among the different models. Compared to the LAMs, the ECMWF analysis (not shown) shows weaker wind speed maxima, especially over the Ionian Sea and along the Tyrrhenian coast. This is probably a consequence of the coarser resolution that smoothes the wind field and determines, of course, a significant loss of small scale details compared with the LAMs. A rotation of the wind from SE to NE is mainly confined over the Tyrrhenian Sea and the north-western side of the Ionian Sea. BOLAM and MOLOCH predict a strong wind curl in the Ionian Sea, with a significant northerly component on the western side (Fig. 3a, b), missing in the ECMWF wind field. Due to the finer resolution, the wind pattern is rougher in MOLOCH compared to BOLAM. Finally, the WRF model 


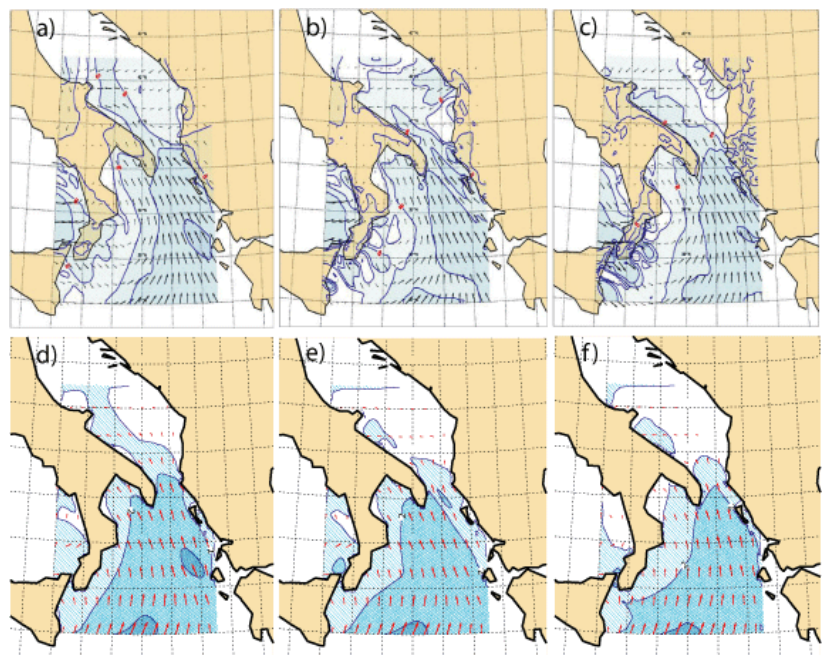

Fig. 4. As in Fig. 3 but at 18:00 UTC, 18 April 2006.

does not reproduce the cyclonic circulation predicted by the other models over the Ionian Sea (Fig. 3c). Therefore, no significant wind curl is simulated there by WRF and the wind remains east-south-easterly also over the Tyrrhenian Sea. The wind speed predicted by WRF is weaker on the Adriatic Sea, while over the Tyrrhenian and the Ionian Sea is slightly more intense. The absence of wind curl over the Ionian Sea in the WRF model simulation may be due to differences in both model setup and physics: for example, the different way to treat the horizontal diffusion or the different treatment of the low level fluxes of heat and humidity, as discussed in Miglietta et al. (2008) and Davolio et al. (2009), can determine significant differences among the two modelling system outputs. The smaller number of vertical levels in the WRF model (Table 1) may also determine a less detailed representation of the physical processes near the surface. As a consequence, the wave height predicted by WAM forced with WRF is 1 meter lower than for the other models in the Adriatic Sea and higher in the Tyrrhenian Sea (Fig. 3d, e, f). Over the Ionian Sea, the area of high waves (higher than $5 \mathrm{~m}$ ) predicted by WAM forced with WRF is larger and shifted to the west compared to BOLAM and MOLOCH.

\section{$4.2 \quad 17-20$ April 2006}

We concentrate our discussion on the different results obtained at 18:00 UTC, 18 April 2006, corresponding to the time of the maximum wave height. All the models agree pretty well in reproducing a cyclonic circulation centred to the west of the Tyrrhenian coast (Fig. 2b). The discrepancies among the different models are of minor importance compared to the previous case study, and concern mainly the intensity of the wind in the different areas. In particular, the ECMWF analysis (not shown) provides slightly stronger wind speeds over the Adriatic and the Ionian Sea during the peak, while all the models predict very close wind speeds over the Tyrrhenian Sea (Fig. 4a, b, c). This result could probably be expected, as this event is characterised by westerly winds over the Tyrrhenian Sea, coming from the lateral western boundary. Since the portion of the Tyrrhenian Sea included in the model domain is very small, the forcing imposed by the boundary conditions dominates the response of the LAMs over the internal model dynamics. Finally, only MOLOCH and WRF predict some localised wind maxima in the southern Ionian Sea, close to the coast of Calabria and Sicily, as only the high-resolution models can resolve the very rough topography of the region, responsible for channelling effects. In general, the wave heights predicted by WAM forced with the ECMWF analysis and BOLAM are a bit larger than for the other models, while the results for MOLOCH and WRF are very close each other (Fig. 4d, e, f).

\subsection{1-4 January 2007}

For the last case, the maxima wave heights are recorded at Cetraro and Monopoli buoys at around 00:00 UTC, 3 January 2007. At that time, the forecast wind fields suggest the presence of a pressure minimum, centred on the east side of the Adriatic Sea, close to the coasts of Montenegro and Albania. This cyclone was not present in the large-scale analysis shown in Fig. 2c probably because of the low horizontal resolution. A strong north-westerly wind is present on the western side of the minimum over the Adriatic Sea (Fig. 5a, $\mathrm{b}, \mathrm{c}$ ), close to the south-eastern Italian coasts. The maximum intensity is present in ECMWF (not shown) and WRF (peak larger than $20 \mathrm{~m} \mathrm{~s}^{-1}$ ), while the wind speed is weaker in MOLOCH and BOLAM. A similar pattern occurs over the Ionian Sea. Over the Tyrrhenian Sea, all the models predict very similar wind speeds probably due to the strong forcing provided through the close western boundary (as discussed in Sect. 4.2). As a consequence, the waves predicted by WAM (Fig. 5d, e, f) forced with WRF reach a maximum height of $6 \mathrm{~m}$ along the Italian coast of the southern Adriatic Sea and are significantly higher also in the Ionian Sea. On the contrary, the ingestion of BOLAM and MOLOCH wind fields into WAM brings to a maximum of $5 \mathrm{~m}$ in the same area. Over the southern Tyrrhenian Sea, the forecast wave fields are similar.

\subsection{Comparison with measurements}

A validation of the results has been done comparing the output of the WAM model with in situ measurements. A series of wave measurements was available at that time from the RON (Rete Ondametrica Nazionale; De Boni et al., 1993) Italian buoy network. Out of the whole set of buoys, three were located at a distance between 3 and $5 \mathrm{~km}$ from the coast, in the area of interest for our study: Monopoli, Cetraro, and Crotone (see their position in Fig. 1b). In order to compare these data with the outputs of the wave model, 


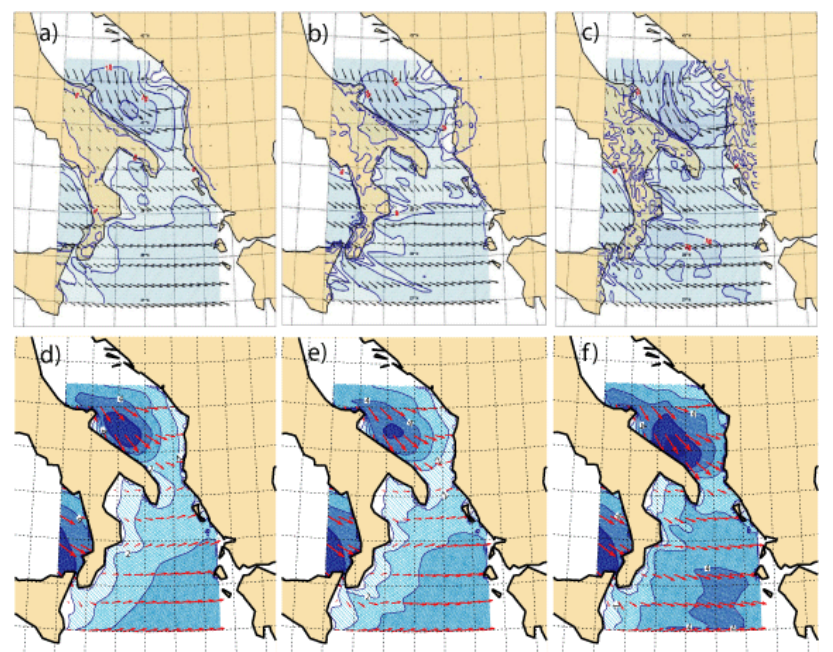

Fig. 5. As in Fig. 3, but at 00:00 UTC, 1 January 2007.

the most significant wave parameters, that is the significant wave height, the mean flow direction and the mean period, have been extracted at the grid point nearest to the position of each buoy for the whole duration of each storm.

In general, a significant improvement in the prediction of wave parameters comes out when the wind field is provided to the wave model by a LAM rather than a GCM. This result is mainly due to the higher horizontal resolution of the LAM and is in agreement with the results of previous studies (Cavaleri et al., 2003, 2006).

The comparison between the models and buoy data shows also that substantial differences occur depending on the direction the waves approach the shore. When the waves approach the coast perpendicularly, model results and measurements are generally in good agreement. This is evident in Fig. 6, where the time evolution of the significant wave height during the three events is presented at the two buoy locations of Crotone and Cetraro. Each coloured line describes the WAM results when forced by the four described wind sources. All the results agree pretty well with the measured data, reproducing correctly the intensity and the evolution of the storms. An exception is the pale blue line (Fig. 6a) representing the wave height at Crotone during the storm of December 2005, obtained by forcing the wave model with the wind forecast by WRF. The overestimation of the peak intensity in this case is due to the absence of the wind curl over the Ionian Sea (see Fig. 3 and Sect. 4.1).

When the waves are parallel to the coast, the differences between model and buoy data are more evident. Figure 7 displays the time evolution of the wave height at Monopoli and Crotone, during the storm of April 2006 and January 2007, respectively. Figures 4 and 5 clearly show the wind blowing (and the wave running) parallel to the coast of the southern Adriatic Sea during both the storms of April 2006 and January 2007, and along the Ionian coast of Calabria close to
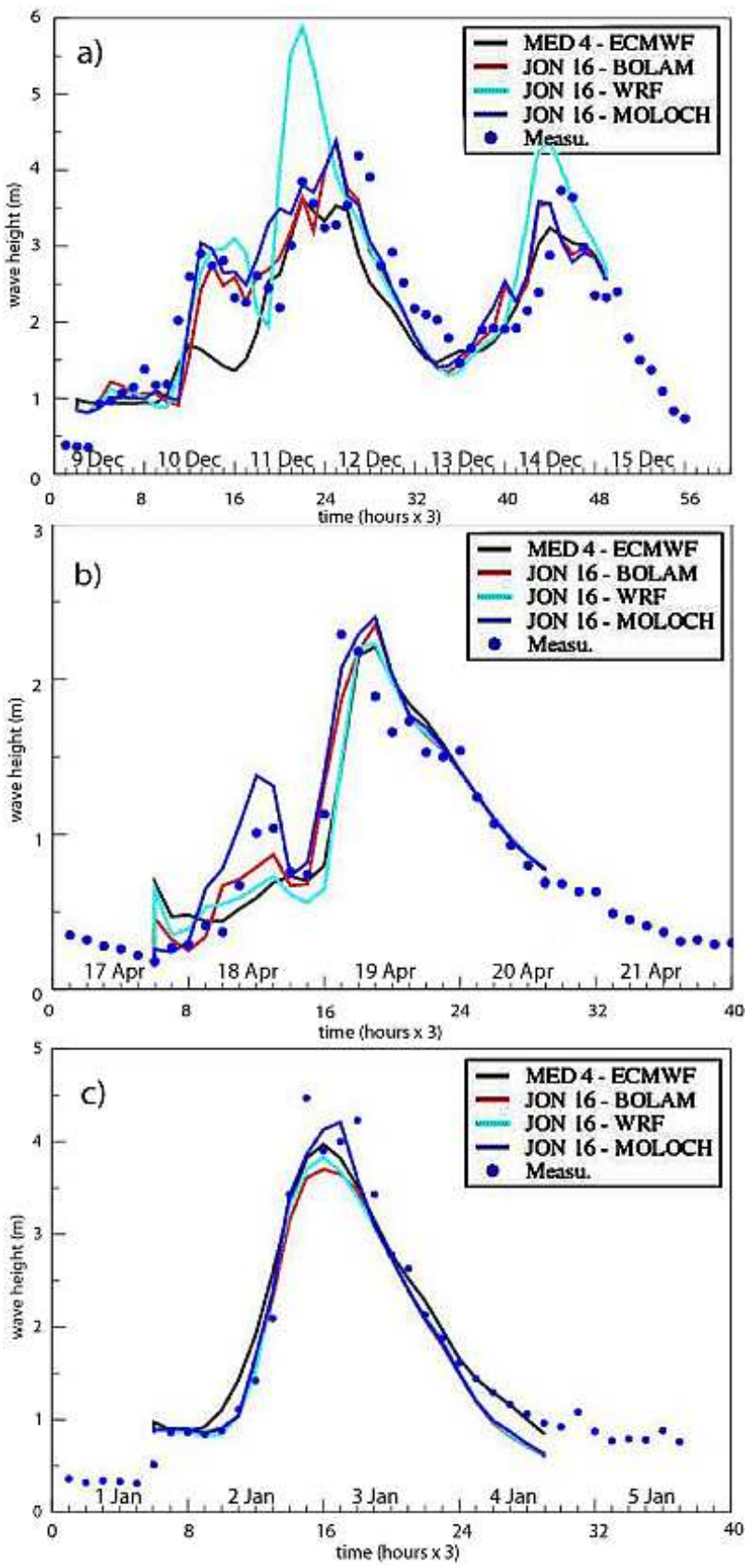

Fig. 6. Time evolution of significant wave height (m) at buoy locations: (a) Crotone, during the storm of December 2005, (b) Cetraro, during the storm of April 2006 and (c) January 2007 (see Fig. 1b for buoy location). The WAM resolution is $1 / 4^{\circ}$ for ECMWF and $1 / 16^{\circ}$ for the limited area models.

Crotone, during January 2007. The main discrepancies in the time evolution can be explained by the different model resolution, as the use of a coarser grid cannot reproduce the strong variability of the wind near the coast. This results in a remarkable error of the wave forecasting when the WAM is forced by the ECMWF wind: the second and main peak at 

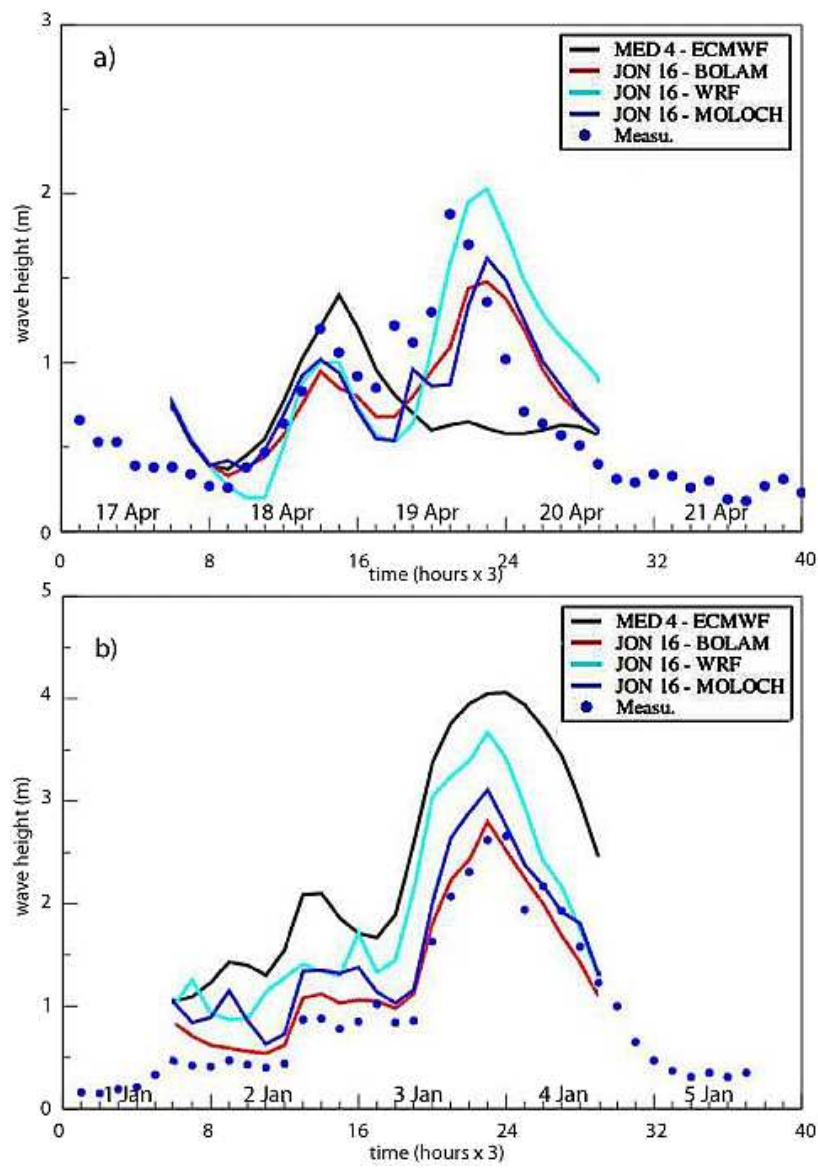

Fig. 7. As in Fig. 6 but at (a) Monopoli, during the storm of April 2006 and (b) Crotone, during the storm of January 2007 (see Fig. 1b for buoy position).

Monopoli observed on April 19 is completely missed and the storm of January 2007 is largely overestimated. Much better results in terms of wave height prediction are obtained when the WAM is forced by the wind fields forecast by higher resolution models. In general, BOLAM and MOLOCH provide slightly better results with respect to WRF.

\section{Conclusions}

Two different modelling chains (BOLAM-MOLOCH and WRF) have been implemented in order to provide forecasts of wind and sea conditions near the coastal areas of southern Italy. Three case studies have been selected and the model results have been compared with measurements. The three selected episodes were characterized by strong winds and severe wave conditions in the Ionian, the southern Adriatic and the southern Tyrrhenian seas. The modelling chains use the same wave model (WAM). WAM is fed with wind fields extracted from the two different limited area meteorological modelling systems. In addition, the ECMWF analysis wind fields are ingested into the wave model for sake of comparison. Figures 3, 4 and 5 show that all the modelling systems are able to reproduce pretty well the time evolution of the $10-\mathrm{m}$ wind, and thus of the wave parameters, although some differences occur among the different model outputs.

The significant wave heights obtained by the different model simulations are compared with the measurements registered at the three buoys located in the area. The results (Figs. 6 and 7) show, as expected, that the ECMWF largescale analyses are not able to capture the detailed structure of the wind, especially close to rough coastlines, where the high-resolution models result to be a more appropriate tool for our purposes. Among the LAMs, the BOLAMMOLOCH modelling system outperforms the version of WRF model adopted in the present study. The analysis of the results point out that the different model outputs are closer to each other and are more skilful in areas where the waves approach the coastline perpendicularly, while their behaviour is more spread and less skilful in cases when wind and waves are running parallel to the coast.

Finally, the previous analysis influenced the choice of the meteorological models employed during the operational forecasting period of RISKMED project. For its best performance, the modelling system BOLAM-MOLOCH has been chosen in order to provide the wind field to WAM. At the moment of the submission of the paper, the forecast provided by the chosen chain is daily presented on the web at the address (www.riskmed.net).

Acknowledgements. The whole work and model tests have been done within the RISKMED project "Weather Risk Reduction in the Central and Eastern Mediterranean" as part of the EU Community Initiative Programme INTERREG IIIB - ARCHIMED.

Edited by: A. Mugnai

Reviewed by: D. Sacchetti and another anonymous referee

\section{References}

Ardhuin, F., Bertotti, L., Bidlot, J. R., Cavaleri, L., Filipetto, V., Lefevre, J. M., and Wittmann, P.: Comparison of wind and wave measurements and models in the Western Mediterranean Sea, Ocean Eng., 34, 526-541, 2007.

Agustsson, H. and Olafsson, H.: forecasting wind gusts in complex terrain, Meteorol. Atmos. Phys., 103, 173-185, 2009.

Cavaleri, L. and Bertotti, L.: The characteristics of wind and wave fields modelled with different resolutions, Q. J. Roy. Meteor. Soc., 129, 1647-1662, 2003.

Cavaleri, L. and Bertotti, L.: The improvement of modelled wind and wave fields with increasing resolution, Ocean Eng., 33, 553565,2006

Davolio, S., Buzzi, A., and Malguzzi, P.: High resolution simulations of an intense convective precipitation event, Meteorol. Atmos. Phys., 95, 139-154, 2007.

Davolio, S., Miglietta, M. M., Moscatello, A., Pacifico, F., Buzzi, A., and Rotunno, R.: Numerical forecast and analysis of a tropical-like cyclone in the Ionian Sea, Nat. Hazards Earth Syst. 
Sci., 9, 551-562, 2009,

http://www.nat-hazards-earth-syst-sci.net/9/551/2009/.

De Boni, M., Cavaleri, L., and Rusconi, A.: The Italian wave measurement network. Proc. of the 23rd Int. Conf. on Coastal Engineering, Venice, Italy, Am. Soc. Civil Eng., 1840-1850, 1993.

Federico, S. and Bellecci, C.: Sea storms hindcast around Calabrian coasts: seven cases study, Il Nuovo Cimento C, 27C, 179-203, 2004.

Federico S., Bellecci, C., Lo Feudo, T., and Arena, F.: Impact of wind field horizontal resolution on sea waves hindcast around Calabrian coasts, Il Nuovo Cimento C, 29C, 147-165, 2006.

Janssen, P. A. E. M.: Progress in ocean wave forecasting, J. Comput. Phys., 227, 3572-3594, 2007.

Komen, G. J., Cavaleri, L., Donelan, M., Hasselmann, K., Hasselmann, S., and Janssen, P. A. E. M.: Dynamics and modelling of ocean waves, Cambridge University Press, 532 pp., 1994.
Miglietta, M. M., Davolio, S., Moscatello, A., Pacifico, F., and Rotunno, R.: The role of surface fluxes in the development of a tropical-like cyclone in southern Italy, Adv. Sci. Res., 2, 35-39, 2008.

Skamarock, W. C., Klemp, J. B., Dudhia, J., Gill, D. O., Barker, D. M., Wang, W., and Powers, J. G.: A description of the Advanced Research WRF Version 2, NCAR Technical Note, 468STR, 88 pp., 2005.

Smith, R. B.: The influence of mountains on the atmosphere, edited by: Saltzman, B., Adv. Geophys., 21, 87-230, 1979.

The WAMDI Group: Hasselmann, S., Hasselmann, K., Bauer, E., Janssen, P. A. E. M., Komen, G., Bertotti, L., Lionello, P., Guillaume, A., Cardone, V., Greenwood, J. A., Reistad, M., Zambresky, L., and Ewing, J. A.: The WAM Model - a third generation ocean wave prediction model, J. Phys. Oceanogr., 18, 1775$1810,1988$. 